\title{
Familial, Anthropometric, and Metabolic Associations of Intramyocellular Lipid Levels in Prepubertal Males
}

\author{
MELLISA A. ASHLEY, ALEXANDRA J. BUCKLEY, ALISON L. CRISS, JULIE A. WARD, \\ ALLAN KEMP, SARAH GARNETT, CHRISTOPHER T. COWELL, LOUISE A. BAUR, AND \\ CAMPBELL H. THOMPSON
}

Department of Paediatrics \& Child Health [M.A.A., L.A.B., C.H.T] and the Human Nutrition Unit, Department of Biochemistry [A.J.B., A.L.C., J.A.W., C.H.T], University of Sydney, Australia; and the Department of Medical Imaging [A.K] and the Ray Williams Institute of Paediatric Endocrinology, Diabetes and Metabolism [S.G., C.T.C], Royal Alexandra Hospital for Children, Westmead, Australia.

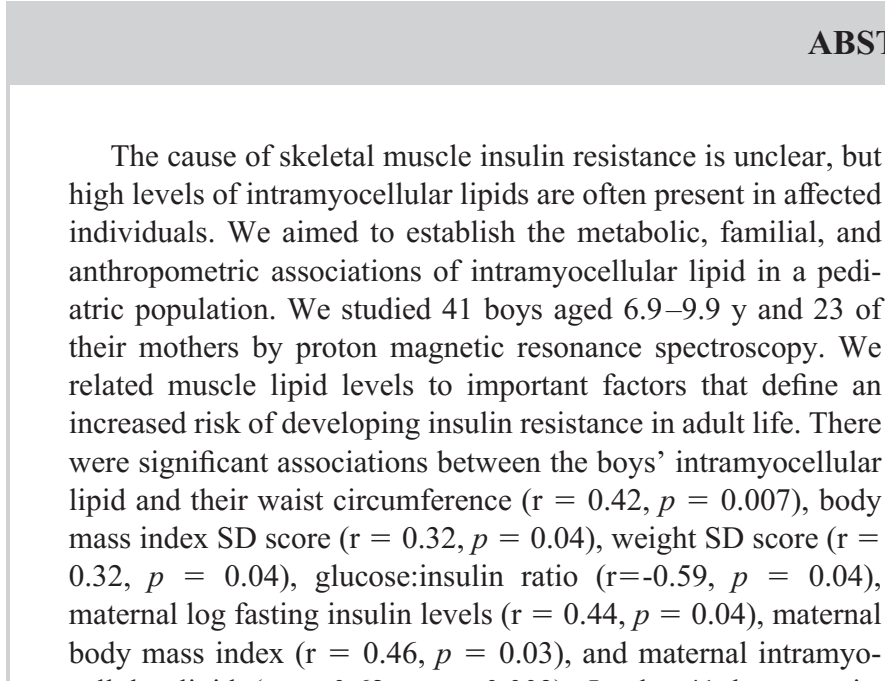
cellular lipid $(\mathrm{r}=0.62, p=0.003)$. In the 41 boys, waist
\end{abstract}

circumference explained $19 \%$ of the variance in the boys' intramyocellular lipid. Maternal intramyocellular lipid explained $39 \%$ of the variance in the boys' intramyocellular lipid in the sub-group of 23 boys. Intramyocellular lipid levels have both metabolic and anthropometric associations in childhood. Before puberty, children develop or inherit muscle metabolic characteristics that are associated both with insulin resistance and risk factors for the development of insulin resistance syndrome in adult life. (Pediatr Res 51: 81-86, 2002)
Abbreviations
IMCL, intramyocellular lipid
WHR, waist: hip ratio
NEFA, non esterified fatty acid

Skeletal muscle insulin resistance is a metabolic abnormality central to the pathogenesis of a cluster of diseases such as type 2 (noninsulin-dependent) diabetes mellitus, dyslipidemia, hypertension, and central obesity. The precise causes of insulin resistance remain uncertain, but both environmental and genetic factors are thought to have a role.

Several studies suggest that morphologic abnormalities of skeletal muscle are associated with the development of insulin resistance (1-3). These abnormalities include elevated levels of IMCL (4-6), an altered proportion of muscle fiber type and decreased capillary density (7-9), abnormalities in capillary structure (10), and an altered fatty acid composition of muscle membranes $(2$,

Received December 6, 2000; accepted July 26, 2001.

Correspondence and reprint requests to: Dr. Campbell Thompson, Human Nutrition Unit, Dept Biochemistry G08, University of Sydney, NSW, 2006, Australia; e-mail: cthompson@biochem.usyd.edu.au

This study was supported by the Diabetes Australia Research Trust, the New Children's Hospital Research Fund, the National Health and Medical Research Council of Australia (grant number 987755), and a Royal Australasian College of Physicians Pharmacia and Upjohn Medical Fellowship.
11). The temporal relationships of these muscle morphologic abnormalities to the onset of insulin resistance and to the appearance of recognized risk factors associated with the development of the insulin resistance syndrome are not clear.

It is possible that some skeletal muscle morphologic abnormalities may precede the development of insulin resistance. For example, infants of mothers with insulin resistance (as determined by maternal fasting insulin levels) have a characteristic muscle membrane fatty acid profile similar to that seen in insulin resistant adults (12). This finding suggests that not only do familial factors play a role in determining muscle membrane composition, but that young children with a high risk of developing insulin resistance in later life may already have a muscle phenotype that is different from those children who are at lower risk. Thus, diseases associated with insulin resistance may have their metabolic antecedents present in early childhood.

The advent of a magnetic resonance-based technique to measure IMCL facilitates studies on muscle lipid metabolism in insulin resistant conditions. Previously, the relationships 
between insulin action and muscle phenotype have been examined primarily with muscle biopsy specimens, whereas proton magnetic resonance spectroscopy enables measurement of IMCL levels in a relatively noninvasive manner $(13,14)$. We studied the soleus muscle, a muscle with fiber orientation amenable to magnetic resonance spectroscopic examination (13) and metabolic associations with whole body insulin sensitivity. Lipid levels within either soleus (15-17) or tibialis anterior muscle cells (15) relate significantly and inversely to whole body insulin sensitivity during a hyperinsulinemic clamp. Soleus IMCL levels can be measured with a coefficient of variation of $8 \%$ to $10 \%$ in our hands and others (18).

The aim of the current study was to investigate the determinants of IMCL levels in healthy children using this novel technique. We examined anthropometry and fasting insulin and glucose levels, factors that are associated with IMCL levels in adults. We also studied the relevance of familial (specifically maternal) factors.

\section{METHODS}

\section{Experimental Subjects}

Forty-one boys aged 6.9-9.9 y were recruited for the studies reported in this paper. Eighteen of the boys were recruited from the Energy Expenditure Study, whose participants were originally recruited from state primary schools in western Sydney (19). An additional 23 boys were recruited from the Nepean Cohort Study, a birth cohort consisting of children born at a gestational age of $>37$ wk at Nepean Hospital in western Sydney between August 1989 and April 1990 (20). The 23 biologic mothers of these boys were also recruited to the study. Note that we deliberately recruited subjects so as to include a wide range of body fatness as judged from previous measurements of body mass index [BMI, weight $/$ height $^{2}$ ] of the participants.

Exclusion criteria were a history of type 1 (insulindependent) or type 2 (noninsulin-dependent) diabetes mellitus within the individual boy, his siblings, or his parents, other chronic illness, or the presence of intra-ocular metal, pacemakers, intra-corporeal ferrous material, or claustrophobia. Informed consent was obtained from all. The study protocol was approved by the Institutional Ethics Committee of the Royal Alexandra Hospital for Children, Westmead.

\section{Protocol}

The clinical studies were performed in the evening at the Royal Alexandra Hospital for Children, Westmead. All subjects were asked to minimize physical activity on the day of the study. All subjects (i.e. 41 boys and 23 mothers) had measurements of IMCL and anthropometry taken. However, wellresolved lipid signals could not be obtained from the muscle of two of the mothers (BMI 25.7 and $35.8 \mathrm{~kg} / \mathrm{m}^{2}$ ). Fasting blood samples were obtained from the boys recruited from the Energy Expenditure Study and from the mothers of the 23 boys participating in the Nepean Cohort Study. Note that, because of ethical and practical constraints, it was not possible to obtain fasting blood samples from all the boys, nor was it possible to perform more detailed metabolic studies on the mothers or the boys.

\section{Anthropometry}

All measurements were performed in duplicate by the one observer (M.A.). Subjects had their height $( \pm 0.1 \mathrm{~cm})$ measured with a Harpenden stadiometer (Holtain Ltd, Crymmych, Dyfed, Wales) and their body weight $( \pm 0.1 \mathrm{~kg})$ measured with a digital scale (A\&D Mercury Pty Ltd, South Australia) while wearing light clothing and no shoes. Weight and height measurements were used to calculate BMI. Each boy's values for weight, height, and BMI were compared with the United States' reference values $(21,22)$ and expressed as SD scores (23) to standardize for differences in age.

Waist and hip circumferences were measured $( \pm 0.1 \mathrm{~cm})$ with a Luftkin thinline tape measure. Waist circumference was measured at the narrowest point between the lower costal border and the iliac crest. Hip circumference was measured at the level of the greatest posterior protuberance of the buttocks (24). These values were used to calculate the WHR. The mean value for each anthropometric measurement was used in all analyses. Intraclass (within observer) correlation coefficients, based on duplicate measurements taken on the same day, were $>0.99$ for height, weight, hip, and waist circumference.

Information on the birth weight, birth length, and ponderal index at birth [birth weight/birth length ${ }^{3}$ ] of the sons was obtained from the records of the Nepean Cohort Study (20) or the personal health records of the boys, as appropriate.

\section{Blood Collection}

A venous blood sample was obtained from the mothers following an 8-h period of fasting. These samples were analyzed for serum insulin, glucose, NEFAs, and triglyceride concentrations. In the boys recruited from the Energy Expenditure Study, a $1 \mathrm{~mL}$ capillary blood sample was obtained from a finger after application of a topical local anesthetic following a 6 hour period of fasting. These samples were analyzed for serum insulin and glucose. Six blood samples were not obtained (i.e. 12 samples were obtained).

\section{In Vivo ${ }^{1} \mathrm{H}$ - Magnetic Resonance Spectroscopy}

Image guided, localized ${ }^{1} \mathrm{H}$ magnetic resonance spectra of the soleus muscle were obtained (1.5 Tesla magnetic resonance scanner, Philips Medical Systems, The Netherlands). The subject lay supine in the magnet with a $\mathrm{C} 3$ circular local coil placed under their right lower leg, positioned within the isocenter of the magnet. Cross sectional images were taken to determine the placement of the $1.5 \times 1.5 \times 5.0 \mathrm{~cm}^{3}$ voxel. Spectra were obtained using a point resolved spectroscopy sequence with echo time/repetition time $=32 / 5000 \mathrm{~ms}, 64$ measurements, and 1024 data points. The peak intensities of the creatine signal $(3.02 \mathrm{ppm})$ and IMCL signal $(1.32 \mathrm{ppm})$ were measured and expressed as a ratio (15). 


\section{Analytical Methods}

Biochemical tests of the blood samples were performed in the Department of Biochemistry, The University of Sydney. Serum glucose concentrations were measured using the glucose oxidase method. Serum insulin concentrations were measured using a double antibody RIA (commercial kit from Linco Research Inc, St. Louis, MO, U.S.A.). The glucose:insulin ratio has been validated and widely used in children as a measure of insulin sensitivity $(25,26)$ and was derived by dividing the fasting glucose level by the fasting insulin level in each of the 23 mothers and the 12 boys from whom blood samples were obtained. Enzymatic colorimetric methods were used to quantify serum NEFAs (WAKO, Osaka, Japan) and serum triglycerides (GPO-PAP, Boeringer-Mannheim $\mathrm{GmbH}$, Castle Hill, Australia) in the adult samples. All samples were batched to minimize interassay variability.

\section{Statistical Analysis}

Statistical analysis was performed using SPSS/PC version 8.0 (SPSS, Chicago, IL, U.S.A.). Data are presented as mean \pm SD. An unpaired $t$ test was used to compare the mean BMI SD score of the boys with the reference population. The distribution of each variable was checked for normality. If not normal, data were log-transformed. Pearson product-moment correlations (r) were calculated and a $p$ value $<0.05$ was taken to indicate a significant association. Multiple regression was used to develop models that predicted the major determinants of IMCL levels in both the group of 41 boys and the group of 23 adult women. The potential predictors that were tested included anthropometric variables, age, serum biochemical measures, and birth size parameters.

\section{RESULTS}

The anthropometric characteristics and IMCL levels of the study participants are shown in Table 1. The mean BMI SD scores of the 41 boys were not significantly different from zero, indicating that the boys' BMI levels were comparable to the reference population. Of the women in the study, $22 \%$ were within the healthy weight range, defined by a BMI $<25 \mathrm{~kg} / \mathrm{m}^{2}$, $43 \%$ were classified as overweight with a BMI of $25-30 \mathrm{~kg} / \mathrm{m}^{2}$,

Table 1. Anthropometric characteristics and intramyocellular lipid (IMCL) levels of the 41 boys and the 23 mothers. Data are expressed using measurements from 41 boys and 23 mothers except where indicated.

\begin{tabular}{lcc}
\hline & Mothers & Boys \\
\hline Age (years) & $39.0 \pm 4.9$ & $9.1 \pm 0.7$ \\
Weight $(\mathrm{kg})$ & $79.2 \pm 14$ & $34.8 \pm 8.0$ \\
Weight SD score & - & $1.00 \pm 1.3$ \\
Height $(\mathrm{cm})$ & $166 \pm 6.5$ & $138 \pm 8.2$ \\
Height SD score & - & $0.88 \pm 1.2$ \\
BMI $\left(\mathrm{kg} / \mathrm{m}^{2}\right)$ & $28.7 \pm 4.9$ & $18.2 \pm 3.0$ \\
BMI SD score & - & $0.31 \pm 0.98$ \\
Waist measurement $(\mathrm{cm})$ & $82.7 \pm 9.9$ & $61.4 \pm 6.9$ \\
Waist:hip ratio & $0.76 \pm 0.06$ & $0.85 \pm 0.05$ \\
IMCL: creatine ratio & $5.9 \pm 2.3$ & $3.6 \pm 1.8$ \\
& $(n=21)$ & \\
\hline
\end{tabular}

Values are mean $\pm \mathrm{SD}$. and $35 \%$ were obese with a BMI of $>30 \mathrm{~kg} / \mathrm{m}^{2}$. The results of the biochemical tests of the mothers and the 12 boys are shown in Table 2. The mean birth weight of the 41 boys was $3632 \pm$ $493 \mathrm{~g}$, the mean birth length was $515 \pm 25 \mathrm{~mm}$, and the mean ponderal index was $26.5 \pm 2.7 \mathrm{~kg} / \mathrm{m}^{3}$. There was no significant difference in current anthropometry or birth size characteristics between the two groups of boys (Nepean Cohort Study group and the Energy Expenditure Study group).

\section{IMCL in Boys}

A significant positive correlation was found between the boys' IMCL levels and waist circumference $(n=41, \mathrm{r}=0.42$, $p=0.007$; Fig. 1). A significant positive correlation was also found between the boys' IMCL levels and both their BMI SD score $(n=41, \mathrm{r}=0.32, p=0.04)$ and weight SD score $(n=$ $41, \mathrm{r}=0.32, p=0.04)$. However, no significant correlation was found between the boys' IMCL levels and any of the other anthropometric variables, including birth size parameters.

Analysis of the serum biochemistry data obtained from the subset of 12 boys revealed a significant inverse correlation between the boys' glucose:insulin ratio and their IMCL levels $(n=12, \mathrm{r}=-0.59, p=0.042$; Fig. 2). Significant inverse correlations were also found between the boys' glucose:insulin ratio and both their weight SD score $(n=12, \mathrm{r}=-0.80, p=$ $0.002)$ and BMI SD score $(n=12, \mathrm{r}=-0.65, p=0.022)$.

\section{Familial Associations}

There were significant correlations found between the sons' IMCL levels and maternal IMCL levels $(n=21, \mathrm{r}=0.62, p=$ 0.003; Fig. 3), maternal BMI $(n=23, \mathrm{r}=0.46, p=0.026)$, maternal $\log$ fasting insulin $(n=23, \mathrm{r}=0.44, p=0.038)$, and maternal glucose:insulin ratio $(n=23, \mathrm{r}=-0.44, p=0.036)$. A positive trend was found between the sons' IMCL and maternal body weight $(n=23, \mathrm{r}=0.41 p=0.055)$. No significant correlations were found between the sons' IMCL levels and any other measured maternal parameter. Significant correlations were also found between the sons' BMI SD score and maternal BMI ( $n=23, \mathrm{r}=0.50, p=0.016)$ and the sons' waist circumference and maternal waist circumference $(n=$ $23, \mathrm{r}=0.44, p=0.036$ ).

Stepwise regression analysis of all potential predictors of the boys' IMCL levels was undertaken using the subjects from the Nepean Cohort Study to include familial factors. Maternal IMCL level was the most significant predictor of the sons' IMCL levels and independently explained $39 \%$ of the variance $(p=0.003)$. Waist circumference was not a significant predictor of IMCL levels during analysis of the Nepean Cohort Study subjects alone, but when the combined group of boys

Table 2. Laboratory characteristics of the mothers $(n=23)$ and the subset of boys $(n=12)$

\begin{tabular}{lcc}
\hline & Mothers & Sub-set of boys \\
\hline Insulin $(\mathrm{pmol} / \mathrm{L})$ & $39 \pm 17$ & $70 \pm 45$ \\
Glucose $(\mathrm{mmol} / \mathrm{L})$ & $5.3 \pm 0.7$ & $4.3 \pm 1.0$ \\
NEFA $(\mathrm{mmol} / \mathrm{L})$ & $1.25 \pm 0.35$ & - \\
Triglyceride $(\mathrm{mmol} / \mathrm{L})$ & $1.22 \pm 0.31$ & - \\
\hline
\end{tabular}

Values are mean $\pm \mathrm{SD}$. 


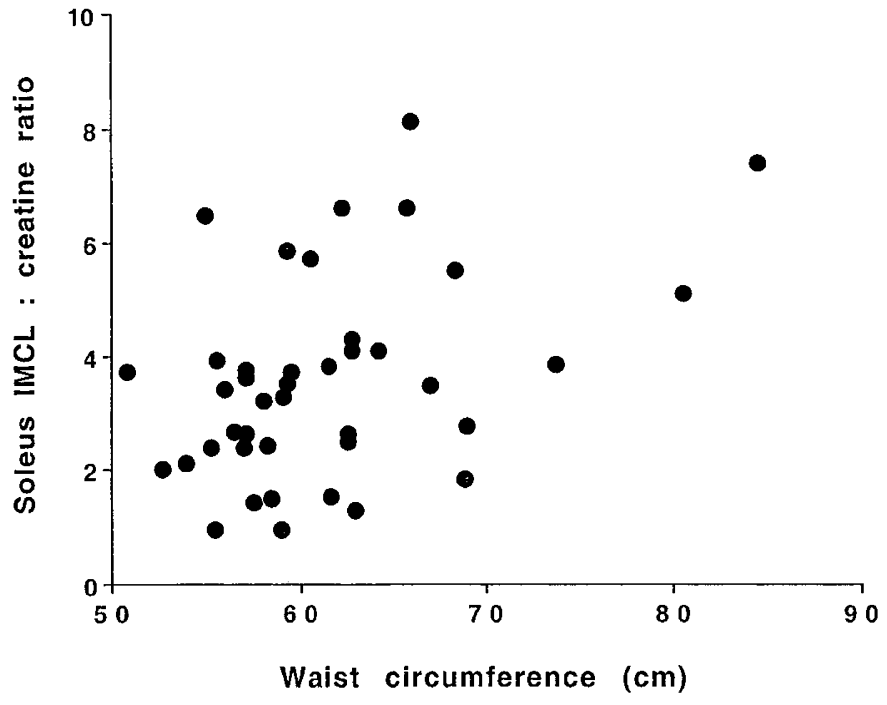

Figure 1. The relationship of IMCL, expressed relative to muscle creatine levels, in the boys to their waist circumference; $n=41, \mathrm{r}=0.42, p=0.007$.

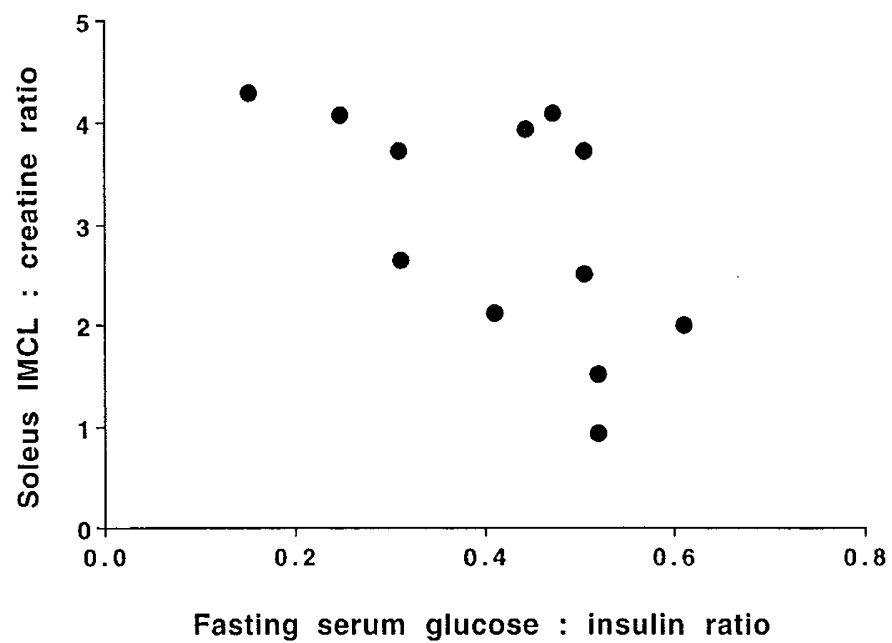

Figure 2. The relationship of IMCL, expressed relative to muscle creatine levels, in the boys to their fasting glucose:insulin ratio; $n=12, \mathrm{r}=-0.59, p$ $=0.042$.

(i.e. $n=41$ ) was considered and adjusted for age, the boys' waist circumference explained $19 \%$ of the variance $(p=$ 0.017). No other variables (maternal or sons') explained any additional variance when added to the respective models.

\section{IMCL in Adult Women}

In the adult women, there was a significant correlation between maternal IMCL levels and fasting log maternal insulin levels $(n=21, \mathrm{r}=0.63, p=0.002)$, maternal glucose:insulin ratio $(n=21, \mathrm{r}=-0.56, p=0.008)$, and maternal waist circumference $(n=21, \mathrm{r}=0.47, p=0.032)$. There was a positive trend between maternal IMCL and maternal WHR ( $n$ $=21, \mathrm{r}=0.42, p=0.056)$. No significant correlation was found between maternal IMCL levels and any other measured maternal parameter.

The only significant predictor of maternal IMCL was fasting log maternal insulin levels, and this information explained $40 \%$

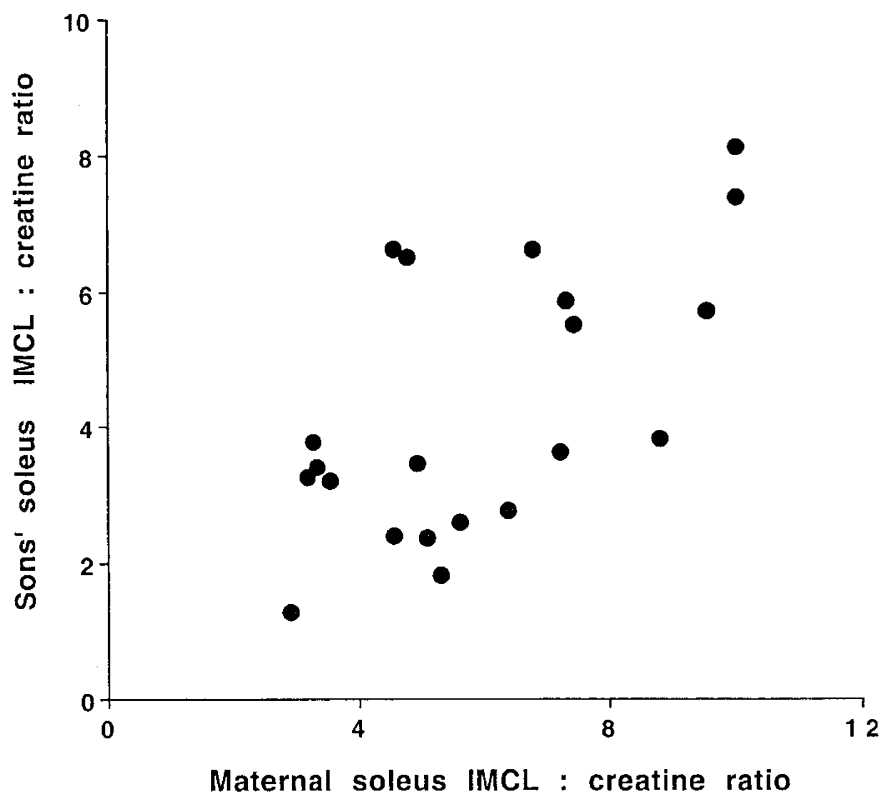

Figure 3. The relationship of IMCL, expressed relative to muscle creatine levels, in the boys and their mothers; $n=21, \mathrm{r}=0.62, p=0.003$.

of the variance $(p=0.002)$. Including other maternal variables into the model did not significantly improve this association.

\section{DISCUSSION}

\section{IMCL Levels in Prepubertal Males}

This study demonstrated an association in healthy children between waist circumference and elevated IMCL levels. We have also demonstrated significant associations between the child's IMCL levels and a measure of their own insulin sensitivity as well as maternal IMCL levels, maternal insulin sensitivity, and maternal anthropometry. Our study has established that IMCL levels have metabolic and anthropometric associations in childhood and that there is a significant familial component defining IMCL levels. These findings are further evidence that the metabolic antecedents to the insulin resistance syndrome lie in childhood, if not earlier.

Current anthropometry. In the group of 41 boys, there were significant correlations between IMCL level and aspects of their current anthropometry. Waist circumference is a simple and relatively accurate measure of abdominal (i.e. both visceral and s.c.) adiposity in children (27). Both weight and BMI SD scores, the other two anthropometric measures that correlated with IMCL level, are not independent of waist circumference, as they both indirectly reflect excess fat deposition in a child. A relationship between raised IMCL and both BMI and visceral fat volume, as determined by dual energy x-ray absorptiometry, has previously been demonstrated in male Caucasian adults (16).

A number of factors other than current anthropometry have been suggested as possible predictors for the risk of a child developing insulin resistance syndrome in adult life. These factors include the child's own fasting glucose and insulin levels, birth size (birth weight or ponderal index) and several parental parameters, including fasting glucose and insulin lev- 
els and parental anthropometry $(12,28-31)$. We examined selected factors that might be predictive of prepubertal male IMCL levels by examining two separate subgroups of our population.

Familial factors. In the group of 23 boys from the Nepean Cohort Study we found a significant positive correlation between IMCL levels in prepubertal males and the following maternal parameters: IMCL, BMI, body weight, and two markers of insulin sensitivity (fasting insulin and glucose:insulin ratio). We are unable to tell from our study whether the familial associations noted are due to shared environmental effects or due to inheritance. Studies upon adult twins have shown that an individual's BMI, WHR, and insulin sensitivity are under significant heritable influence $(32,33)$. Therefore, the relationship between IMCL in mother and child might be directly inherited, might arise indirectly from the inheritance of BMI, WHR, or insulin sensitivity characteristics, or might be due to shared environmental factors.

The significant inverse correlation between maternal log fasting insulin and the sons' IMCL levels is of particular interest. This association suggests that children may have familial muscle metabolic characteristics that are associated with the insulin resistant syndrome and which are evident from an early age. An earlier study supports this finding (12).

Cardiovascular risk factors, including insulin levels and BMI, tend to track from childhood through to adulthood (34, 35). It is therefore possible that the elevated IMCL levels in the boy, as well as the elevated BMI, waist circumference, and weight, may persist into adulthood and predict increased central adiposity for that boy as an adult. The presence of elevated IMCL levels in a child may be a risk factor for developing the insulin resistance syndrome in adult life, even in normal weight men.

Insulin sensitivity. We found a significant association between prepubertal IMCL and glucose:insulin ratio. The glucose:insulin ratio is a valid measure of insulin sensitivity in children and relates closely to other pediatric measures of insulin sensitivity such as the i.v. glucose tolerance test or hyperinsulinemic clamp (26). Ethical considerations precluded our performing more detailed measures of insulin action on our subjects. Nevertheless, we believe that the association between the glucose:insulin ratio and IMCL implies that muscle metabolism is already abnormal in the prepubertal insulin resistant population. Thus, IMCL levels have both metabolic and anthropometric associations in childhood.

Intrauterine factors. This study found no association between the prepubertal boys' IMCL levels and their birth size parameters. Low birth weight and a low ponderal index at birth have previously been associated with features of insulin resistance syndrome in the adult population $(30,31,36,37)$. Fetal malnutrition may result in permanent changes in muscle that lead to abnormalities of insulin action; however, these changes in muscle do not appear to include the accumulation of IMCL stores (6). The lack of relationship between IMCL and birth size in our study may be due to small sample size, but our data would also support the suggestion that the mechanism by which small babies become insulin resistant differs from the mechanism of development of insulin resistance associated with abdominal obesity and IMCL accumulation (6).

In the group as a whole, waist circumference explained 19\% of the variance in the boys' IMCL, although it was not a significant predictor in analysis of the subjects from the Nepean Cohort Study alone. Within that smaller, Nepean Cohort Study group, maternal IMCL explained 39\% of the variance in the boys' IMCL. This relationship suggests that familial factors might have more influence than the child's current anthropometry on IMCL levels.

\section{IMCL levels in adult females}

Within the adult female population studied, there was a significant positive correlation observed between log fasting insulin and IMCL levels and a negative correlation between glucose:insulin ratio and IMCL levels. Several other studies have reported the association between elevated IMCL stores and reduced insulin sensitivity $(4-6,15-17,24)$. The correlation in adult females between their waist circumference or WHR and their IMCL levels supports our observation in children and others' observations in adult males (16) that abdominal adiposity is associated with IMCL levels.

In summary, we have shown that in prepubertal boys, IMCL levels are significantly predicted by their own abdominal adiposity (as assessed by waist circumference) and insulin sensitivity (as assessed by glucose:insulin ratio). Maternal IMCL levels, maternal BMI, and maternal insulin sensitivity also predict IMCL levels in prepubertal boys. It would appear that before puberty, children develop or inherit muscle metabolic characteristics that are associated both with insulin resistance and with accepted risk factors for the development of insulin resistance syndrome in adult life.

Acknowledgments. The authors thank Dr. Jennifer Peat for advice on statistical analysis for this study and Mrs. Jenny Phuyal and Mr. Kieron Rooney for expert technical assistance.

\section{REFERENCES}

1. Kriketos AD, Pan DA, Lillioja S, Cooney GJ, Baur LA, Milner MR, Sutton JR, Jenkins AB, Bogardus C, Storlien LH 1996 Interrelationships between muscle morphology, insulin action, and adiposity. Am J Physiol 270:R1332-R1339

2. Borkman M, Storlien LH, Pan DA, Jenkins AB, Chisholm DJ, Campbell LV 1993 The relationship between insulin sensitivity and the fatty acid composition of phospholipids of skeletal muscle. N Engl J Med 328:238-244

3. Pan DA, Lillioja S, Milner MR, Kriketos AD, Baur LA, Bogardus C, Storlien LH 1995 Skeletal muscle membrane lipid composition is related to adiposity and insulin action. J Clin Invest 96:2802-2808

4. Falholt K, Jensen I, Lindkaer Jensen S, Mortensen H, Volund A, Heding LG, Noerskov Petersen P, Falholt W 1988 Carbohydrate and lipid metabolism of skeletal muscle in type 2 diabetic patients. Diabet Med 5:27-31

5. Storlien LH, Jenkins AB, Chisholm DJ, Pascoe W, Khouri S, Kraegen E 1991 Influence of dietary fat composition on development of insulin resistance in rats: relationship to muscle triglyceride and $\omega 3$ fatty acids in muscle phospholipid. Diabetes 40:280-289

6. Phillips DIW, Caddy S, Ilic V, Fielding BA, Frayn KN, Borthwick AC, Taylor R 1996 Intramuscular triglyceride and muscle insulin sensitivity: evidence for a relationship in nondiabetic subjects. Metabolism 45:947-950

7. Lillioja S, Young AA, Culter CL, Ivy JL, Abbott WG, Zawadzki JK, Yki-Jarvinen H, Christin L, Secomb TW, Bogardus C 1987 Skeletal muscle capillary density and fiber type are possible determinants of in vivo insulin resistance in man. J Clin Invest $80: 415-424$

8. Marin P, Andersson B, Krotkiewski M, Bjorntorp P 1994 Muscle fiber composition and capillary density in women and men with NIDDM. Diabetes Care 17:382-386

9. Lithell H, Lindgarde F, Hellsing K, Lundqvist G, Nygaard E, Vessby B, Saltin B 1981 Body weight, skeletal muscle morphology and enzyme activities in relation to fasting 
serum insulin concentration and glucose tolerance in 48-year-old men. Diabetes 30:19-25

10. Feingold KR, Browner WS, Siperstein MD 1989 Prospective studies of muscle capillary basement membrane width in prediabetics. J Clin Endocrinol Metab 69:784-789

11. Baur LA, O'Connor J, Pan DA, Kriketos AD, Storlien LH 1998 The fatty acid composition of skeletal muscle membrane phospholipid: its relationship with the type of feeding and plasma glucose levels in young children. Metabolism 47:106-112

12. Baur LA, O'Connor J, Pan DA, Storlien LH 1999 Relationships between maternal risk of insulin resistance and the child's muscle membrane fatty acid composition. Diabetes 48:112-116

13. Boesch C, Slotboom J, Hoppeler H, Kreis R 1997 In vivo determination of intramyocellular lipids in human muscle by means of localized ${ }^{1} \mathrm{H}-\mathrm{MR}$-spectroscopy. Magn Reson Med 37:484-493

14. Perseghin G, Scifo P, de Cobelli F, Pagliato E, Battezzati A, Arcelloni C, Vanzulli A, Testolin G, Pozza G, Del Maschio A, Luzi L 1999 Intramyocellular triglyceride content is a determinant of in vivo insulin resistance in humans. Diabetes 48:16001606

15. Jacob S, Machann J, Rett K, Brechtel K, Volk A, Renn W, Maerker E, Matthaei S, Schick F, Claussen CD, Haring HU 1999 Association of increased intramyocellular lipid content with insulin resistance in lean nondiabetic offspring of type 2 diabetic subjects. Diabetes 48:1113-1119

16. Forouhi NG, Fenkinson G, Thomas EL, Mullick S, Mierisova S, Bhonsle U, McKeigue PM, Bell JD 1999 Relation of triglyceride stores in skeletal muscle cells to central obesity and insulin sensitivity in European and South Asian men. Diabetologia 42:932-935

17. Krssak M, Falk Petersen K, Dresner A, DiPietro L, Vogel SM, Rothman DL, Roden M, Shulman GI 1999 Intramyocellular lipid concentrations are correlated with insulin sensitivity in humans: a ${ }^{1} \mathrm{H}$ NMR spectroscopy study. Diabetologia 42:113-116

18. Szczepaniak LS, Babcock EE, Schick F, Dobbins RL, Garg A, Burns DK, McGarry D, Stein DT 1999 Measurement of intracellular triglyceride stores by ${ }^{1} \mathrm{H}$ spectroscopy: validation in vivo. Am J Physiol 276:E977-E989

19. Baur LA, Ball EJ, O'Connor J Steinbeck KS, Gaskin KJ, Wishart C, Davies PSW 2000 Physical activity, energy expenditure \& body fatness in 6-8 year old children. Int J Obesity 24(suppl 1):S30

20. Garnett S, Cowell CT, Bradford D Lee J, Tao C, Patrauskas V, Fay R, Baur LA 1999 Effects of gender, body composition and birth size on IGF-1 in 7 and 8 year old children. Hormone Res 52:221-229

21. World Health Organization 1983 Reference data for weight and height of children. In: Measuring Change in Nutritional Status. World Health Organization, Geneva, pp 61-101

22. Hammer LD, Kraemer HC, Wilson DM, Ritter PL, Dornbusch SM 1991 Standardised percentile curves of body-mass index for children and adolescents. Am J Dis Child $145: 259-263$
23. Dibley MJ, Staehling NW, Nieburg P, Towbridge FL 1987 Interpretation of z-score anthropometric indicators derived from the international growth reference. Am J Clin Nutr 46:749-762

24. Norton K, Whittingham N, Carter L. Kerr D, Gore C, Marfell-Jones M 1996 Measurement techniques in anthropometry. In: Norton K, Olds T (eds) Anthropometrica. A Textbook of Body Measurements for Sports and Health Courses. University of New South Wales, Sydney, pp 25-75

25. Jiang X, Srinivasan SR, Radhakrishnamurthy B, Dalferes ER, Berenson GS 1996 Racial (black-white) differences in insulin secretion and clearance in adolescents: the Bogalusa heart study. Pediatrics 97:357-360

26. Vuguin P, Saenger P, DiMartino-Nardi J 1998 Fasting glucose:insulin ratio: A useful measure of insulin resistance in girls with premature adrenarche. J Clin Exp Med $83: 2608$

27. Taylor RW, Jones IE, Williams SM, Goulding A 2000 Evaluation of waist circumference, waist-to-hip ratio, and the conicity index as screening tools for high trunk fat mass, as measured by dual-energy x-ray absorptiometry, in children aged 3-19 y. Am J Clin Nutr 72:490-495

28. Whitaker RC, Wright JA, Pepe MS, Seidel KD, Dietz WH 1997 Predicting obesity in young adulthood from childhood and parental obesity. N Engl J Med 337:869-873

29. Akerblom HK, Viikari J, Raitakari OT, Uhari M 1999 Cardiovascular Risk in Young Finns Study: general outline and recent developments. Ann Med 31(suppl 1):45-54

30. Hales CN, Barker DJP, Clark PMS, Cox LJ, Fall C, Osmond C 1991 Fetal and infant growth and impaired glucose tolerance at age 64. BMJ 303:1019-1022

31. Barker DJP, Hales CN, Fall CHD, Osmond C, Phipps K, Clark PMS 1993 Type 2 (non-insulin dependent) diabetes mellitus, hypertension and hyperlipidaemia (syndrome X): relation to reduced fetal growth. Diabetologia 36:62-67

32. Lehtovirta M, Kaprio J, Forsblom C, Eriksson J, Tuomilehto J, Groop L 2000 Insulin sensitivity and insulin secretion in monozygotic and dizygotic twins. Diabetologia 43:285-293

33. Poulsen P, Ohm Kyvik K, Vaag A, Beck-Nielsen H 1999 Heritability of Type II (non-insulin-dependent) diabetes mellitus and abnormal glucose tolerance-a population-based twin study. Diabetologia 42:139-145

34. Guo SS, Roche AF, Chumlea WC, Gardner JD, Siervogel RM 1994 The predictive value of childhood body mass index values for overweight at age $35 \mathrm{y}$. Am J Clin Nutr 59:810-819

35. Bao W, Srinivasan SR, Wattigney WA, Berenson GS 1994 Persistence of multiple cardiovascular risk clustering related to syndrome $\mathrm{X}$ from childhood to young adulthood. The Bogalusa Heart Study. Arch Intern Med 154:1842-1847

36. Phillips DIW, Barker DJP, Hales CN, Hirst S, Osmond C 1994 Thinness at birth and insulin resistance in adult life. Diabetologia 37:150-154

37. Lithell HO, McKeigue PM, Berglund L, Mohsen R, Lithell UB, Leon DA 1996 Relation of size at birth to non-insulin dependent diabetes and insulin concentrations in men aged 50-60 years. BMJ 312:406-410 